\title{
Impact of Intracellular Concentrations on Metabolic Drug-Drug Interaction Studies
}

\author{
Andrea Treyer, ${ }^{1}$ (]) Mohammed Ullah, ${ }^{2}$ Neil Parrott, ${ }^{2}$ Birgit Molitor, $^{2}$ Stephen Fowler, ${ }^{2}$ and Per Artursson ${ }^{1,3,4,5}$
}

Received 21 December 2018; accepted 23 May 2019; published online 18 June 2019

\begin{abstract}
Accurate prediction of drug-drug interactions (DDI) is a challenging task in drug discovery and development. It requires determination of enzyme inhibition in vitro which is highly system-dependent for many compounds. The aim of this study was to investigate whether the determination of intracellular unbound concentrations in primary human hepatocytes can be used to bridge discrepancies between results obtained using human liver microsomes and hepatocytes. Specifically, we investigated if $\mathrm{Kp}_{\mathrm{uu}}$ could reconcile differences in CYP enzyme inhibition values $\left(\mathrm{K}_{\mathrm{i}}\right.$ or $\left.\mathrm{IC}_{50}\right)$. Firstly, our methodology for determination of $\mathrm{Kp}_{\mathrm{uu}}$ was optimized for human hepatocytes, using four well-studied reference compounds. Secondly, the methodology was applied to a series of structurally related CYP2C9 inhibitors from a Roche discovery project. Lastly, the $\mathrm{Kp}_{\mathrm{uu}}$ values of three commonly used CYP3A4 inhibitors-ketoconazole, itraconazole, and posaconazole-were determined and compared to compound-specific hepatic enrichment factors obtained from physiologically based modeling of clinical DDI studies with these three compounds. Kp $\mathrm{pu}_{\mathrm{u}}$ obtained in suspended human hepatocytes gave good predictions of system-dependent differences in vitro. The $\mathrm{Kp}_{\mathrm{uu}}$ was also in fair agreement with the compound-specific hepatic enrichment factors in DDI models and can therefore be used to improve estimations of enrichment factors in physiologically based pharmacokinetic modeling.
\end{abstract}

KEY WORDS: drug-drug interaction; intracellular bioavailability; physiologically based pharmacokinetic modeling; scaling factor; unbound drug concentrations.

\section{INTRODUCTION}

Accurate predictions of drug-drug interactions (DDIs) are a challenging task during drug development because the relevant inhibitor concentration is not directly accessible $(1,2)$. Predictions of DDIs depend on in vitro parameters such as the half-maximal inhibitory concentration $\left(\mathrm{IC}_{50}\right)$ or the inhibition constant $\left(\mathrm{K}_{\mathrm{i}}\right)(3)$. These in vitro values are then used in physiologically based pharmacokinetic (PBPK) models to simulate DDIs in vivo (4).

Electronic supplementary material The online version of this article (https://doi.org/10.1208/s12248-019-0344-8) contains supplementary material, which is available to authorized users.

\footnotetext{
${ }^{1}$ Department of Pharmacy, Uppsala University, Box 580, SE-751 23, Uppsala, Sweden.

${ }^{2}$ Roche Pharmaceutical Research and Early Development, Roche Innovation Center Basel, Basel, Switzerland.

${ }^{3}$ Science for Life Laboratory Drug Discovery and Development platform (SciLifelab DDD-P), Uppsala, Sweden.

${ }^{4}$ Uppsala University Drug Optimization and Pharmaceutical Profiling Platform (UDOPP), Uppsala University, Uppsala, Sweden.

${ }^{5}$ To whom correspondence should be addressed. (e-mail: per.artursson@farmaci.uu.se)
}

For predictions of metabolic DDIs with CYP enzymes, $\mathrm{K}_{\mathrm{i}}$ or $\mathrm{IC}_{50}$ values for a given compound are typically determined in liver microsomes or in hepatocytes. There is a growing interest in using cryopreserved human hepatocytes $(\mathrm{HH})$ instead of human liver microsomes (HLM) for preclinical DDI assessment. In the microsomal setting, the drug concentration available to interact with the enzyme is equal to the unbound drug concentration in the incubation medium (i.e., the nominal incubation concentration, $\mathrm{C}_{\mathrm{inc}}$, corrected for fraction of unbound drug in the liver microsomes $\left(f_{u, m i c}\right)$ ) (5). However, the $\mathrm{HH}$ model may be a more physiologically relevant system than HLM, because it takes into account multiple processes that influence enzyme inhibition. In the hepatocyte setting, compounds need to reach the cell interior where the CYP enzymes are located, a process that may involve passive permeability and active transport. Subsequent to this, the intracellular unbound drug concentration $\left(\mathrm{C}_{\mathrm{u}, \mathrm{cell}}\right)$ may be further influenced by metabolic clearance, protein binding, and partitioning into organelles (e.g., lysosomal trapping) or cellular membranes (58). These factors can all contribute to inconsistencies between the $\mathrm{C}_{\mathrm{u} \text {,cell }}$ and $\mathrm{C}_{\mathrm{inc}}$, leading to differences in the $\mathrm{K}_{\mathrm{i} \text {,app }}$ or $\mathrm{IC}_{50 \text {,app }}$ values measured in HLM and HH. Therefore, careful consideration must be given to which in vitro system is appropriate for testing enzyme inhibition. 
Determination of $\mathrm{C}_{\mathrm{u}, \mathrm{cell}}$ is especially challenging if active transport is involved and is therefore classified as a low-confidence parameter in PBPK modeling (9). The US Food and Drug Administration (FDA) and the European Medicines Agency (EMA) recommended the $[\mathrm{I}] / \mathrm{K}_{\mathrm{i}}$ ratio (where $[\mathrm{I}]$ is the inhibitor concentration) as a parameter in static DDI predictions (10). However, the determination of [I] is not currently standardized. The surrogates commonly used are the average or maximum unbound concentration in blood or at the inlet to the liver, or the maximum total concentration in the circulation at steady state (10-12). In addition to the different methods to estimate [I], the determination of $\mathrm{K}_{\mathrm{i}}$ also varies. For example, $\mathrm{K}_{\mathrm{i}, \text { app }}$-based on determinations in cryopreserved $\mathrm{HH}$ suspended in human plasma-has been proposed (13). Such systems aim to reduce in vitro to in vivo translational uncertainties by more closely mimicking the in vivo situation, building protein binding and intracellular bioavailability considerations into the in vitro system.

Strategies for more direct estimations of $\mathrm{C}_{\mathrm{u}, \text { cell }}$ recently emerged (14-18). These include the parallel determination of hepatocellular drug accumulation at steady state $(\mathrm{Kp})$ and the unbound fraction of drug in the cell $\left(f_{u, c e l l}\right)$ which are combined to calculate the unbound partition coefficient $K \mathrm{~K}_{\mathrm{uu}}$. $\mathrm{K} \mathrm{p}_{\mathrm{uu}}$ is defined as the ratio between unbound drug concentration in the cell interior and the unbound drug concentration in the cell exterior at steady state and can also be derived from kinetic parameters (17).

We recently introduced the term intracellular bioavailability $\left(F_{i c}\right)$, defined as the ratio between the intracellular unbound concentration, which is available to elicit effects inside the cell, and the extracellular concentration. In the present work, $\mathrm{F}_{\mathrm{ic}}$ is equal to $\mathrm{Kp}_{\mathrm{uu}}$, as no protein was added to the incubation media, and therefore, the term $\mathrm{Kp}_{\mathrm{uu}}$ has been used for simplicity. $\mathrm{F}_{\mathrm{ic}}$ or $\mathrm{Kp}_{\mathrm{uu}}$ account for active and passive mechanisms and predict target engagement and phenotypic responses in cells (19). We have shown that this parameter reflects transporter effects in cell lines transfected with single transporters. Further, we have seen differences in the $\mathrm{Kp}_{\mathrm{uu}}$ values for freshly isolated, plated $\mathrm{HH}$, and suspended $\mathrm{HH}$. This is explained by the altered clearance in the two systems (7).

Given this strong influence of culture formats on $\mathrm{Kp}_{\mathrm{uu}}$, we hypothesized that $\mathrm{Kp}_{\mathrm{uu}}$ could be used to reconcile the differences in measurement obtained from different humanrelevant experimental systems. We therefore first investigated a series of reference CYP inhibitors (saquinavir, nelfinavir, enoxacin, and clarithromycin) in HLM and HH, previously shown to have differences in $\mathrm{K}_{\mathrm{i} \text {,app }}$ in rat liver microsomes and rat hepatocytes $(20,21)$. Second, we applied an optimized assay for a series of investigational compounds from a drug discovery program that were all identified as CYP2C9 inhibitors. Finally, $\mathrm{Kp}_{\mathrm{uu}}$ was determined for a series of commonly used CYP inhibitors of the azole antifungal family-ketoconazole, itraconazole, and posaconazole. These compounds were chosen because they require hepatic enrichment factors (referred to as "hepatic uptake value" in the SimCYP software), to reconcile in vitro and in vivo $\mathrm{K}_{\mathrm{i}}$ values $(11,22)$. We reasoned that these scaling factors represent $\mathrm{Kp}_{\mathrm{uu}}$ at the site of DDI.

\section{METHODS}

\section{Chemicals}

Compounds were retrieved from the in-house stock at the Roche laboratories at their highest available purity and dissolved at $10 \mathrm{mM}$ in DMSO or, if lower, at their highest solubility. DMSO stocks were kept at $-20^{\circ} \mathrm{C}$.

\section{Compound Selection}

The literature was screened for a validation set of compounds with reported discrepancies between cellular and microsomal $\mathrm{IC}_{50}$ or $\mathrm{Ki}$ values. Enoxacin, clarithromycin, saquinavir, and nelfinavir were identified as suitable candidates (20). The method was then applied to an internal compound set from Roche (hereafter RO compounds) consisting of a structurally related series known to inhibit CYP2C9, and for which information on $\mathrm{IC}_{50}$ in $\mathrm{HLM}$ and $\mathrm{HH}$ was available. As a third compound set, three members of the azole antifungal family-ketoconazole, itraconazole, and posaconazole-were identified as compounds with reported in vitro $\mathrm{K}_{\mathrm{i}}$ values that differ from the $\mathrm{K}_{\mathrm{i}}$ values reported in models predicting in vivo data.

\section{Cell Culture}

A pooled $\mathrm{HH}$ batch (BioreclamationIVT, LiverPool 10donor $\mathrm{HH}$, product no. X008001, Lot RBR) was used in the CYP inhibition assay and for determination drug uptake in suspended HH. After thawing, the cells were suspended in InVitroGro CP medium at the specified concentration in each assay (product no. Z99029, BioreclamationIVT) and used immediately for experiments.

\section{CYP Inhibition Assay in HLM and HH}

For determination of CYP2C9 inhibition, $180 \mu \mathrm{L}$ of HLM 0.2 mg/mL (BD Gentest, Cat no. 452117, pool from 150 donors of mixed gender) plus substrate $(5 \mu \mathrm{M}$ diclofenac for CYP2C9 and $5 \mu \mathrm{M}$ midazolam for CYP3A4) was added to a deep 96-well plate together with the test compound or reference inhibitor (concentration range from $0.008 \mu \mathrm{M}$ to $1 \mu \mathrm{M})$. After the addition of $20 \mu \mathrm{L}$ of $10 \mathrm{mM}$ NADPH, the plate was incubated for $5 \mathrm{~min}$. The reaction was stopped by adding $200 \mu \mathrm{L}$ of acetonitrile containing an internal standard. After centrifugation of $10 \mathrm{~min}$ at $6200 \times \mathrm{g}$, the concentration of the substrate in the samples was determined by LC-MS (Sciex API4000, see S6 for LC-MS parameters).

For $\mathrm{HH}, 50 \mu \mathrm{L}$ of a suspension of cryopreserved $\mathrm{HH}$ $\left(3 \times 10^{6}\right.$ cells $\left./ \mathrm{mL}\right)$ were added to a $96-$ well round bottom plate and pre-incubated for $20 \mathrm{~min}$ in Williams E medium (without FBS). Fifty microliters of a $\times 3$ concentrated test compoundsolution and $50 \mu \mathrm{L}$ of $\times 3$ concentrated substrate (diclofenac for CYP2C9, midazolam for CYP3A4 and tacrine for CYP1A2) were added and the plate was incubated on a shaker at $37^{\circ} \mathrm{C}, 5 \% \mathrm{CO}_{2}$, and $900 \mathrm{rpm}$. Incubations were stopped after $5 \mathrm{~min}$ by transferring $100 \mu \mathrm{L}$ of the suspension to a fresh plate and adding $100 \mu \mathrm{L}$ of acetonitrile containing the internal standard and then analyzed as above. 
Where available, $\mathrm{IC}_{50}$ values were compared to values found in the literature (Table S1).

\section{Intracellular Unbound Drug Accumulation Ratio (Kpuu}

$\mathrm{Kp}_{\mathrm{uu}}$ was determined as previously described $(7,18)$ using Eq. (1):

$\mathrm{Kp} \mathrm{puu}_{\mathrm{uu}}=\mathrm{Kp} \cdot \frac{\mathrm{f}_{\mathrm{u}, \text { cell }}}{\mathrm{f}_{\mathrm{u} \text {,medium }}}$

where $\mathrm{Kp}$ is the steady-state cellular uptake, and $\mathrm{f}_{\mathrm{u}, \mathrm{cell}}$ the fraction of unbound compound in the cell, determined as described below. The fraction unbound of the compound in the medium ( $\mathrm{f}_{\mathrm{u} \text {,medium }}$ ) was equal to 1 as no serum proteins or other drug binding components were added to the incubation media.

\section{Steady-State Cellular Uptake (Kp)}

The $\mathrm{Kp}$ in suspended $\mathrm{HH}$ was measured similarly to previous reports with some modifications $(7,18)$. Briefly, cells were rinsed twice with pre-warmed containing $10 \mathrm{mM}$ HEPES. One hundred microliters of cell suspension $(5 \times$ $10^{6}$ cells $/ \mathrm{mL}$ ) was added to a conical 96-well plate, and $100 \mu \mathrm{L}$ of $1 \mu \mathrm{M}$ drug solutions in Hank's buffered salt solution (HBSS) buffered with $10 \mathrm{mM}$ HEPES was added (resulting in a $0.5 \mu \mathrm{M}$ final concentration). All incubations were performed in triplicates on up to three independent occasions. Full-time curves were established at 1, 3, 7.5, 15, 30, and $45 \mathrm{~min}$ to determine $\mathrm{Kp}$ at equilibrium. For single time point measurements, the incubation time was matched to the CYP inhibition assays. A sample of the medium was removed after centrifugation in a pre-cooled centrifuge at $4^{\circ} \mathrm{C}(100 \times g$, $5 \mathrm{~min}$ ), and ten-fold diluted with a mixture of acetonitrile and water (60:40) containing the internal standard for determination of $\mathrm{C}_{\text {medium}}$. The remaining supernatant was removed by aspiration and cells were washed twice with icecold buffer. The intracellular compound was extracted using the acetonitrile to water to internal standard mixture for determination of the amount of drug in the cells $\left(\mathrm{A}_{\text {cell }}\right)$. Protein content $\left(\mathrm{P}_{\text {cell }}\right)$ was quantified using the BCA assay in representative wells to establish the cellular volume $\left(\mathrm{V}_{\text {cell }}\right)$, assuming $6.5 \mu \mathrm{L} / \mathrm{mg}$ protein (23). Finally, $\mathrm{Kp}$ was calculated using Eq. (2)

$\mathrm{Kp}=\frac{\mathrm{A}_{\text {cell }} /\left(\mathrm{V}_{\text {cell }} \cdot \mathrm{P}_{\text {cell }}\right)}{\mathrm{C}_{\text {medium }}}$

\section{Determination of $f_{u, c e l l}$ and $f_{u, m i c}$}

$\mathrm{f}_{\mathrm{u}, \text { cell }}$ was measured in cassette mode as previously described, but with minor modifications (24). Briefly, frozen cell pellets were thawed on ice and diluted to 10 million cells/ $\mathrm{mL}$ in HBSS containing $10 \mathrm{mM}$ HEPES. The suspension was homogenized using a mini bead beater (Precellys, EQ02520300-RD000.0, bead no. VK01) for 2 cycles of $10 \mathrm{~s}$ with an intermittent time of $30 \mathrm{~s}$. Compounds were added to the cell homogenate at a final concentration of $0.5 \mu \mathrm{M}$ and the spiked homogenate was transferred to a dialysis chamber (Rapid Equilibrium Dialysis Device, Thermo Fisher Scientific). HBSS buffered with $10 \mathrm{mM}$ HEPES was placed in the receptor compartment. Samples of spiked cell homogenate were placed at 4 and $37^{\circ} \mathrm{C}$ for the duration of the experiment for recovery and stability calculations. Incubation time was $4 \mathrm{~h}$ at $37^{\circ} \mathrm{C}$ and $900 \mathrm{rpm}$ for all compounds except itraconazole which reached equilibrium only after $24 \mathrm{~h}$ (Fig. S4). The unbound fraction in the cell homogenate $\left(f_{u, h o m}\right)$ was determined according to Eq. (3):

$\mathrm{f}_{\mathrm{u}, \text { hom }}=\frac{\mathrm{C}_{\text {buffer }}}{\mathrm{C}_{\text {hom }}}$

and the fraction of unbound compound in the cell $\left(\mathrm{f}_{\mathrm{u}, \mathrm{cell}}\right)$ was calculated by correcting for homogenate dilution according to Eq. (4):

$\mathrm{f}_{\mathrm{u}, \text { cell }}=\frac{1}{D \cdot\left(1 / \mathrm{f}_{\mathrm{u}, \text { hom }}-1\right)+1}$

where the dilution constant $D$ was calculated using Eq. (5), and assuming the $\mathrm{V}_{\text {cell }}$ to be equal to $6.5 \mu \mathrm{L} / \mathrm{mg}$ protein (23). $\mathrm{P}_{\text {hom }}$ is the protein concentration of the cell homogenate quantified using the BCA assay.

$D=1 /\left(\mathrm{V}_{\text {cell }} \cdot \mathrm{P}_{\text {hom }}\right)$

The lower detection limit was reached for determination of $f_{u, c e l l}$ below $0.01 \%$, and the binding was assumed to be linear at the concentrations used, based on previous results (18).

For determination of the fraction unbound to microsomes $\left(f_{\mathrm{u}, \mathrm{mic}}\right.$ ), HLM at $0.2 \mathrm{mg} / \mathrm{mL}$ (equivalent concentration to CYP inhibition assay; BD Gentest, Cat no. 452117, pool from 150 donors of mixed gender) were used instead of cell homogenate and calculated in analogy to $\mathrm{f}_{\mathrm{u} \text {,hom }}$ (Eq. 3).

\section{Determination of Molecular Properties}

Molecular properties of literature compounds were determined using ADMET predictor (Simulations Plus, version 7.2) and cross-checked to values published in the public databases DrugBank (25) and PubChem (http:// pubchem.ncbi.nlm.nih.gov). Molecular properties ( $\log D$, charge, PSA) of RO compounds were calculated using Roche proprietary in silico tools.

\section{Statistical Analysis}

All statistical analyses were performed in Graph-Pad Prism (version 7.04).

\section{RESULTS}

\section{Method Optimization}

Four reference compounds of different chemical character were studied first. The physicochemical properties of these 
Table I. Major Physicochemical Properties and Results in HLM and Suspended HH. Kp, $\mathrm{f}_{\mathrm{u}, \text { cell }}$, and $\mathrm{f}_{\mathrm{u}, \mathrm{mic}}$ in Rat Liver Microsomes and Hepatocytes Derived from the Literature Are Summarized in S3. Transporter and Enzyme Substrates Are Indicated in Table S7

\begin{tabular}{llllllll}
\hline Compound & $\mathrm{MW}(\mathrm{g} / \mathrm{mol})$ & Charge & $\operatorname{LogD} \mathrm{D}_{7.4}$ & $\mathrm{f}_{\mathrm{u}, \mathrm{mic}}$ & $\mathrm{f}_{\mathrm{u}, \text { cell }}$ & $\mathrm{Kp}$ & $\mathrm{Kpuu}$ \\
\hline Enoxacin & 320.32 & Zwitter & -1.1 & $0.53 \pm 0.13$ & $1.0 \pm 0.0$ & $7.4 \pm 1.1$ & $7.4 \pm 0.2$ \\
Clarithromycin & 747.95 & Basic & 1.6 & $0.40 \pm 0.08$ & $0.10 \pm 0.04$ & $25.9 \pm 2.1$ & $2.7 \pm 0.4$ \\
Saquinavir & 670.84 & Neutral & 3.5 & $0.15 \pm 0.07$ & $0.00030 \pm 0.00006$ & $109 \pm 12$ & $0.030 \pm 0.002$ \\
Nelfinavir & 567.78 & Neutral & 4.6 & $0.04 \pm 0.02$ & $0.00025 \pm 0.00005$ & $956 \pm 312$ & $0.24 \pm 0.03$ \\
\hline
\end{tabular}

drugs are summarized in Table I. Enoxacin and clarithromycin are poorly metabolized, hydrophilic drugs while saquinavir and nelfinavir are extensively metabolized, lipophilic drugs (26). All four have been previously shown to have a clear difference in their $K_{i, \text { app }}$ values for liver microsomes and suspended hepatocytes in the rat (Table S1). This made these compounds suitable for investigation in human liver microsomes (HLM) and hepatocytes $(\mathrm{HH})$. The fraction unbound of the four compounds to HLM $\left(\mathrm{f}_{\mathrm{u}, \mathrm{mic}}\right)$ was determined using equilibrium dialysis and compared to $f_{u, m i c}$ in rat liver microsomes (Fig. 1a, Table S3). $\mathrm{Kp}_{\mathrm{uu}}$ in suspended $\mathrm{HH}$ was determined by combining $\mathrm{Kp}$ and $\mathrm{f}_{\mathrm{u}, \text { cell }}$ (Table I). $\mathrm{Kp} \mathrm{puu}_{\mathrm{u}}$ in rat hepatocytes was derived from $\mathrm{Kp}$ values from the literature (Table S3). Enoxacin and clarithromycin had $\mathrm{Kp}_{\mathrm{uu}}$ values above 1, indicating that they accumulated in HH. In contrast, saquinavir and nelfinavir had Kp $p_{u u}$ values below 1 (Fig. 1b).

Next, we used the $\mathrm{f}_{\mathrm{u} \text {,mic }}$ and $\mathrm{Kp}_{\mathrm{uu}}$ values in human and rat to scale apparent $\mathrm{K}_{\mathrm{i}}$ (or $\mathrm{IC}_{50}$ ) values determined in microsomes and hepatocytes, respectively. Before scaling, these apparent values revealed a significant discrepancy between hepatocytes and microsomes, with the differences ranging up to 22-fold (Fig. 1c). To obtain corrected $\mathrm{K}_{\mathrm{i}}$ or $\mathrm{IC}_{50}$, we multiplied apparent $\mathrm{K}_{\mathrm{i}}$ or $\mathrm{IC}_{50}$ in microsomes with $\mathrm{f}_{\mathrm{u} \text {,mic }}$ and apparent $\mathrm{K}_{\mathrm{i}}$ or $\mathrm{IC}_{50}$ in hepatocytes with $\mathrm{Kp}_{\mathrm{uu}}(=\mathrm{Kp} \times$ $\left.\mathrm{f}_{\mathrm{u} \text {,cell }}\right)$. After applying these corrections, $\mathrm{K}_{\mathrm{i} \text {,app }}$ or $\mathrm{IC}_{50 \text {,app }}$ values could largely be reconciled (i.e., $\sim 2$-fold differences). Nelfinavir-the most lipophilic compound in the a

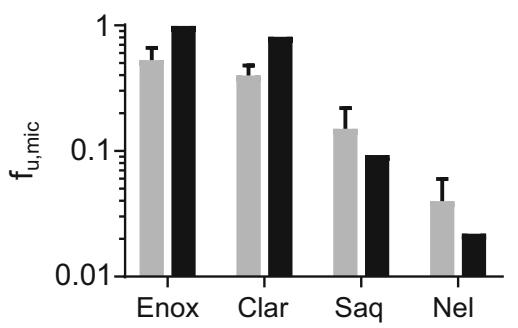

C
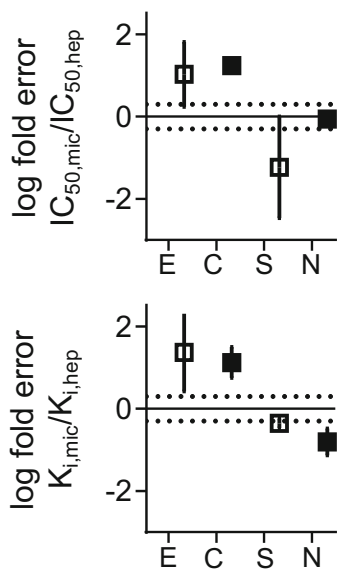

corrected for $\mathrm{f}_{\mathrm{u}, \mathrm{mic}}$
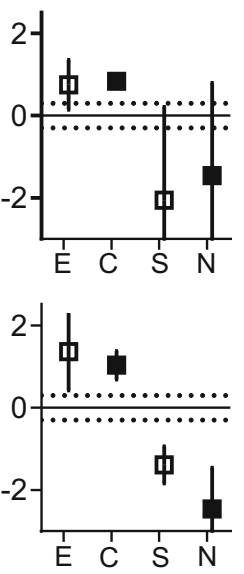

b

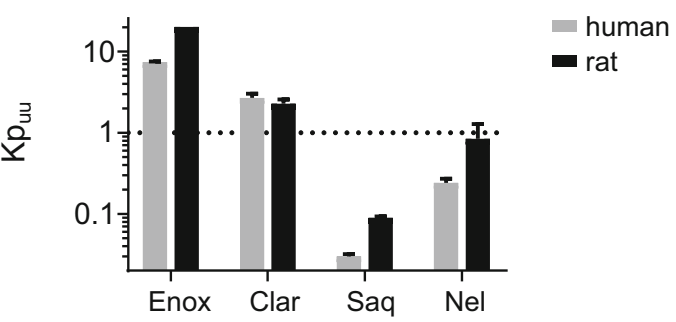

corrected for $\mathrm{Kp}_{\mathrm{uu}}$

corrected for $\mathrm{f}_{\mathrm{u} \text {,mic }}$ and $\mathrm{Kp}_{\mathrm{uu}}$
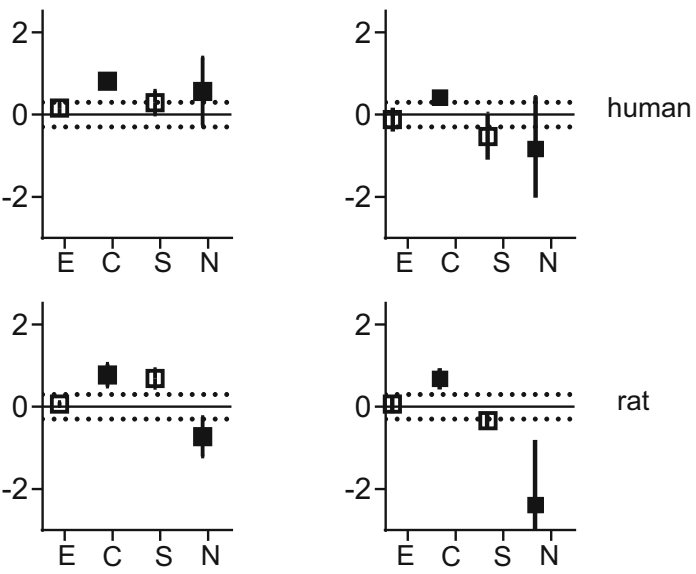

Fig. 1. a Comparison of $\mathrm{f}_{\mathrm{u} \text { mic }}$ in human vs. rat liver microsomes. Rat values are derived from Brown et al. (20). b Comparison of $\mathrm{Kp}_{\mathrm{uu}}$ in human vs. rat hepatocytes. c Log fold difference of apparent and corrected (unbound) $\mathrm{IC}_{50}$ determined in human liver microsomes and human hepatocytes or $\mathrm{K}_{\mathrm{i}}$ determined in rat microsomes and rat hepatocytes. The dotted lines represent a 2 -fold difference. Error bars represent standard deviations. Apparent and corrected $\mathrm{K}_{\mathrm{i}}$ or $\mathrm{IC}_{50}$ values are presented in Tables S1 and S2. Enox, E: enoxacin; Clar, C: clarithromycin; Saq, S: saquinavir; Nel, N: nelfinavir 
a<smiles>NC(=O)NS(=O)(=O)NC1CCCCC1</smiles>
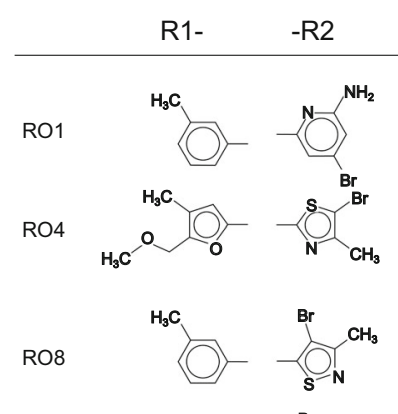

$\mathrm{RO} \mathrm{H}_{3} \mathrm{C}$

R1- $-R 2$

$\mathrm{RO} 2$

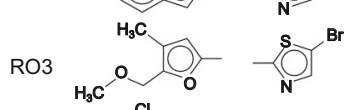
RO5

RO6

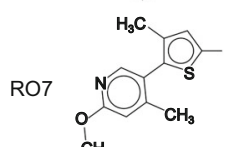

$\mathrm{CH}_{3}$ b apparent $\mathrm{IC}_{50}$

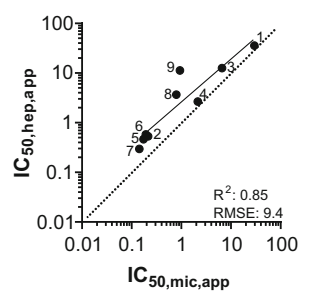

d corrected, $\mathrm{Kp}_{\mathrm{uu}}$ only

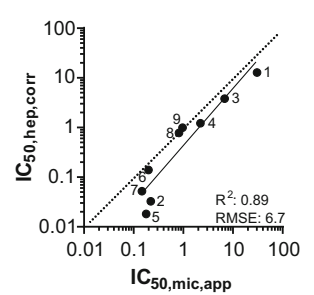

C corrected, $\mathrm{f}_{\mathrm{u}, \mathrm{mic}}$ only

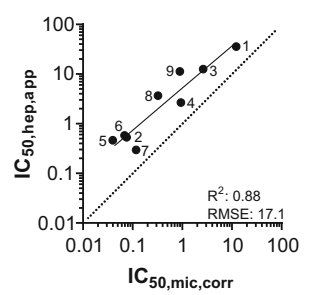

Fig. 2. $\mathrm{Kp}_{\mathrm{uu}}$ as correction factor of $\mathrm{IC}_{50}$ in the RO discovery series. a Structures of RO discovery compound. b-e Comparison of $\mathrm{IC}_{50}$ values measured in HLM and $\mathrm{HH}$. Hepatocellular $\mathrm{IC}_{50 \text {,app }}$ were corrected with $\mathrm{Kp}_{\mathrm{uu}}\left(=\mathrm{Kp} \cdot \mathrm{f}_{\mathrm{u} \text {,cell }}\right)$ in suspended $\mathrm{HH}$ and microsomal $\mathrm{IC}_{50 \text {,app }}$ values were corrected with $\mathrm{f}_{\mathrm{u} \text {,mic }}$ to obtain $\mathrm{IC}_{50 \text {,corr }}$. The dotted line indicates the line of unity. The labels of the data points correspond to the structure numbers in panel (a)

series-appeared to be an outlier since after correction for $\mathrm{f}_{\mathrm{u} \text {,mic }}$ and $\mathrm{Kp}_{\mathrm{uu}}$, the difference in $\mathrm{K}_{\mathrm{i}}$ or $\mathrm{IC}_{50}$ increased rather than decreased.

\section{$\mathrm{Kp}_{\mathrm{uu}}$ as Scaling Factor of $\mathrm{IC}_{\mathbf{5 0}}$ for an $\mathrm{RO}$ Discovery Series Inhibiting CYP2C9}

We further applied our approach to an internal compound set (RO compounds). The nine compounds in this discovery series were outliers in the internal screening processes in which $\mathrm{IC}_{50}$ values of $\mathrm{HH}$ and HLM were compared. The compounds of this series are known to inhibit CYP2C9. These nine compounds are structurally related, with a common core structure containing a sulfonamide and a secondary amide, and aromatic substituents including (iso)thiazoles, benzothiophenes, pyridines, or furanes (Fig. 2a). They are all acidic at $\mathrm{pH} 7.4$, with $\log \mathrm{D}$ values indicating hydrophilic properties (Table II).

First, we determined the $\mathrm{IC}_{50 \text {,app }}$ in $\mathrm{HH}$ and HLM using diclofenac as substrate. The $\mathrm{IC}_{50}$ values of $\mathrm{RO} 1, \mathrm{RO} 3$, and
RO4 were identical for HH and HLM, while the other compounds differed up to 12-fold (RO9) (Fig. 2b), with, a root-mean-squared error (RMSE) of 9.4 for $\mathrm{IC}_{50 \text {,hep,app }}$

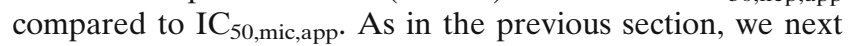
determined $\mathrm{Kp}_{\mathrm{uu}}$ and $\mathrm{f}_{\mathrm{u} \text {,mic }}$ taking care to use the same batches of hepatocytes and microsomes as for the inhibition experiments, respectively (Table II). All parameters were matched to the $\mathrm{IC}_{50}$ assay.

We then used the $\mathrm{Kp}_{\mathrm{uu}}$ and $\mathrm{f}_{\mathrm{u} \text {,mic }}$ values as scaling factors to determine $\mathrm{IC}_{50 \text {,corr }}$. Correction using $\mathrm{Kp}_{\mathrm{uu}}$ or $\mathrm{f}_{\mathrm{u} \text {,mic }}$ alone did not improve the correlations (Fig. 2c and d). After combining $\mathrm{Kp}_{\mathrm{uu}}$ and $\mathrm{f}_{\mathrm{u} \text {,mic }}$ to give $\mathrm{IC}_{50 \text {,hep,corr }}$ and $\mathrm{IC}_{50 \mathrm{mic}, \text { corr }}$, respectively, the linear correlation between the $\mathrm{IC}_{50}$ values improved, giving and $R^{2}$ of 0.92 and a 10 -fold reduction in RMSE from 9.4 to 0.9 (Fig. 2e).

Because the compounds were analogous to each other, we also analyzed the possible influence of substituents on $\mathrm{Kp}_{\mathrm{uu}}$. For instance, in five of the nine compounds, the R2 substituent was kept constant while the R1 substituent varied. However, no systematic influence of the change in substituent

Table II. Properties of the RO Discovery Compound Series and Results in HLM and Suspended HH

\begin{tabular}{|c|c|c|c|c|c|c|c|c|c|c|}
\hline Compound & MW (g/mol) & Charge & $\log \mathrm{D}_{7.4}$ & PSA & $\mathrm{pKa}$ & $\mathrm{P}_{\mathrm{app}}\left(\times 10^{-6} \mathrm{~cm} / \mathrm{s}\right)$ & $\mathrm{f}_{\mathrm{u}, \mathrm{mic}}$ & $\mathrm{f}_{\mathrm{u}, \text { cell }}$ & $\mathrm{Kp}$ & $\mathrm{Kp}$ uu \\
\hline RO01 & 385.24 & Acidic & 0.7 & 123 & 5.41 & 10 & $0.42 \pm 0.06$ & $0.0149 \pm 0.0003$ & $24.0 \pm 2.2$ & $0.357 \pm 0.003$ \\
\hline $\mathrm{RO} 02$ & 432.34 & Acidic & 1 & 153 & 3.14 & 2 & $0.36 \pm 0.09$ & $0.00130 \pm 0.00007$ & $47.3 \pm 1.1$ & $0.0613 \pm 0.0002$ \\
\hline RO03 & 410.26 & Acidic & -1 & 147 & 2.91 & 9 & $0.41 \pm 0.03$ & $0.017 \pm 0.001$ & $17.9 \pm 8.9$ & $0.30 \pm 0.08$ \\
\hline RO04 & 424.29 & Acidic & -0.7 & 147 & 2.80 & 13 & $0.45 \pm 0.11$ & $0.02 \pm 0.01$ & $27.6 \pm 26.1$ & $0.46 \pm 0.65$ \\
\hline RO05 & 452.75 & Acidic & 1.1 & 153 & 2.76 & 2 & $0.23 \pm 0.02$ & $0.0021 \pm 0.0003$ & $18.5 \pm 4.4$ & $0.039 \pm 0.003$ \\
\hline RO06 & 415.29 & Acidic & 0.4 & 130 & 2.80 & 3 & $0.36 \pm 0.11$ & $0.0039 \pm 0.0003$ & $61.6 \pm 38.6$ & $0.24 \pm 0.10$ \\
\hline RO07 & 503.41 & Acidic & 0.9 & 175 & 3.17 & 4 & $0.84 \pm 0.06$ & $0.00392 \pm 0.00003$ & $41.9 \pm 4.8$ & $0.16 \pm 0.01$ \\
\hline RO08 & 390.28 & Acidic & -0.1 & 125 & 2.66 & 22 & $0.41 \pm 0.09$ & $0.009 \pm 0.004$ & $22.2 \pm 4.3$ & $0.21 \pm 0.05$ \\
\hline RO09 & 454.38 & Acidic & -0.3 & 162 & 2.49 & 2 & $0.97 \pm 0.41$ & $0.0075 \pm 0.0006$ & $11.7 \pm 2.0$ & $0.088 \pm 0.003$ \\
\hline
\end{tabular}




\begin{tabular}{|c|c|c|c|}
\hline a Compound & DDI study & Ratio & nomenclature in publication \\
\hline \multirow[t]{4}{*}{ Ketoconazole } & Yamano (1998), rat & 1.3 & $\begin{array}{l}\text { "liver-unbound concentration to } \\
\text { plasma-unbound concentration" }\end{array}$ \\
\hline & Iwasaki (2017), rat & 4 to 8 & $\begin{array}{l}\text { "unbound liver concentration to } \\
\text { unbound hepatic vein }\end{array}$ \\
\hline & Sim-CYP model description file & 6 (SimCYP, early version) & $\begin{array}{l}\text { concentration" } \\
\text { "hepatic uptake value" interpreted }\end{array}$ \\
\hline & and Pathak (2017), human & 2.07 (version 15) & as scalar for $f_{u}$ in the liver \\
\hline \multirow[t]{2}{*}{ Itraconazole } & Yamano $(1988,2001)$, rat & 11 to 14 & $\begin{array}{l}\text { "liver-unbound concentration to } \\
\text { plasma-unbound concentration" }\end{array}$ \\
\hline & Isoherranen (2004), human & 12 & $\mathrm{~K}_{\mathrm{i}}$ vs $\mathrm{K}_{\mathrm{i}, \mathrm{u}}$ \\
\hline Posaconazole & Cleary (2017), human & 10 to 26 & "in vitro vs. in vivo $\mathrm{K}_{\mathrm{i}}$ " \\
\hline
\end{tabular}

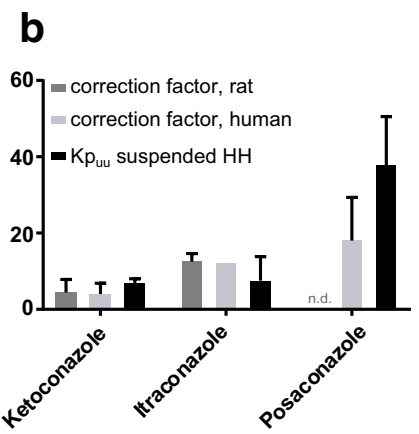

Fig. 3. Correlation of IVIVE correction factors with $\mathrm{Kp}_{\mathrm{uu}}$. a Overview of correction factors used for the azole antifungal compounds in in vivo DDI studies. b Illustration of hepatic uptake scalars in rat and human DDI models (error bars represent range) vs. in vitro $\mathrm{Kp}_{\mathrm{uu}}$ in suspended $\mathrm{HH}$ (error bars represent $\mathrm{SD}$ )

could be observed. We conclude that the compound series was too small to allow a proper substituent analysis; this underscores the importance of experimental analysis of small series of compounds.

\section{Kpu in IVIVE and DDI Models of the Azole Antifungal Family}

Finally, we investigated if $\mathrm{Kp}_{\mathrm{uu}}$ could improve predictions by DDI models that are based on in vitro $\mathrm{K}_{\mathrm{i}}$ values. Compounds of the azole family are commonly used as inhibitors of CYP3A4 in preclinical and clinical DDI studies $(2,27)$. A concentrative cellular uptake of ketoconazole, itraconazole, and posaconazole has been widely described, but uptake mechanisms are not fully elucidated (28-31). This concentrative uptake requires correction of $\mathrm{K}_{\mathrm{i}}$ (which is typically determined in HLM) in order to match in vivo $\mathrm{K}_{\mathrm{i}}$ values in DDI models. Therefore, compound-specific correction factors (referred to as "hepatic enrichment factor" or "hepatic uptake scalar") have been introduced to improve the IVIVE in several models, which are summarized in Fig. 3a. We therefore investigated if $\mathrm{Kp}_{\mathrm{uu}}$ values measured in suspended $\mathrm{HH}$ agreed with these correction factors (Table III and Fig. $3 \mathrm{~b}$ ). The $\mathrm{Kp}_{\text {uu }}$ values were high, ranging from 7 to 38, in line with the previously described concentrative uptake. Interestingly, the $\mathrm{Kp}_{\mathrm{uu}}$ values were within 2-fold of the empirically determined correction factors in the DDI models, indicating that $\mathrm{Kp}_{\mathrm{uu}}$ is a major contributor to the "hepatic enrichment factor" for the azole series.

\section{DISCUSSION}

In this work, we evaluated the potential of $\mathrm{Kp}_{\mathrm{uu}}$ as scaling factor for CYP enzyme inhibition studies, using three experimental setups.
For the first set of compounds, we investigated if the determination of intracellular unbound concentrations could be used to reconcile differences in potency in CYP inhibition observed between microsomes and hepatocytes. CYP enzymes can be considered as targets or off-targets facing the cell interior. We have previously shown that $\mathrm{F}_{\mathrm{ic}}$ or $\mathrm{Kp}_{\mathrm{uu}}$ can explain differences in potency between isolated intracellular targets in biochemical high-throughput screening assays and the corresponding cellular assays (19). Drug response for intracellular targets in a variety of subcellular compartments including the cytosol, endosomes, and the nucleus has been successfully predicted, using our methodology for determination of $F_{\text {ic }}, F_{\text {cyto }}$, or $F_{\text {endo }}(19,32)$. Intracellular unbound drug concentrations are determined by combining the cellular accumulation ratio $(\mathrm{Kp})$ with the fraction of unbound compound in the cell $\left(\mathrm{f}_{\mathrm{u}, \mathrm{cell}}\right)$. $\mathrm{f}_{\mathrm{u}, \text { cell }}$ is determined using the homogenization method which relies on the assumption that the degree of unspecific binding of drugs is not altered upon homogenization of cells $(7,18)$.

In the first series of experiments, we used reference compounds with previously reported differences in $\mathrm{K}_{\mathrm{i}}$ of CYPs in rat liver microsomes and rat hepatocytes, as well as $\mathrm{Kp}, \mathrm{f}_{\mathrm{u}, \text { cell }}$, and $\mathrm{f}_{\mathrm{u} \text {,mic }}$ values in the rat (20).

Our experimental human $\mathrm{f}_{\mathrm{u}, \mathrm{cell}}$ values differed more than 100 -fold for the two lipophilic drugs compared to those in the rat study that was calculated based on lipophilicity and cellular volume (33) (saquinavir 0.14 vs. 0.0003 and nelfinavir 0.035 vs. 0.0002 , rat $v s$. human, respectively, Table S3). There was a better agreement for the two more hydrophilic compounds (enoxacin 0.99 vs. 1.00 and clarithromycin $0.86 \mathrm{vs}$. 0.10 in rat vs. human, respectively). The homogenization/membrane dialysis method has been compared with the temperature and lipophilicity methods for estimating the $f_{u, c e l l}$ of a limited series of structural unrelated compounds by Riede et al. (15). In their study, the homogenization method gave generally lower values than the

Table III. Properties and Results for the Azole Antifungal Series and Results in HLM and Suspended HH

\begin{tabular}{|c|c|c|c|c|c|c|c|}
\hline Compound & MW (g/mol) & Charge & $\log D_{7.4}$ & $\mathrm{f}_{\mathrm{u}, \mathrm{mic}}$ & $\mathrm{f}_{\mathrm{u}, \text { cell }}$ & $\mathrm{Kp}$ & $\mathrm{Kp} \mathrm{puu}_{\mathrm{u}}$ \\
\hline Ketoconazole & 531.43 & Neutral & 3.7 & $0.32 \pm 0.12$ & $0.004 \pm 0.001$ & $1659 \pm 479$ & $6.9 \pm 1.1$ \\
\hline Itraconazole & 705.63 & Neutral & 4.9 & $0.21 \pm 0.13$ & $0.003 \pm 0.002$ & $2717 \pm 1573$ & $7.5 \pm 6.3$ \\
\hline Posaconazole & 700.78 & Neutral & 4.4 & $0.21 \pm 0.11$ & $0.005 \pm 0.003$ & $6931 \pm 1235$ & $37.6 \pm 12.8$ \\
\hline
\end{tabular}


temperature and lipophilicity methods. This suggests an overestimation of intracellular binding by the latter two. However, a large variability (up to 13-fold differences) between laboratories has been observed $(7,15,17,34,35)$. $\mathrm{f}_{\mathrm{u} \text {,cell }}$ is dependent on accurate dilution factors for scaling $\mathrm{f}_{\mathrm{u}, \mathrm{hom}}$ to $\mathrm{f}_{\mathrm{u}, \text { cell }}$ (Eq. 4 and 5). In the comparative study by Riede et al. (15), very low cell concentrations $(130,000$ cells $/ \mathrm{mL})$ were used, in comparison to 10 million cells $/ \mathrm{mL}$ in our studies or 50 million cells/mL by Riccardi et al. $(34,35)$. Such experimental differences may not allow a reliable comparison between laboratories, but in general, all experimental setups agree on significantly lower $\mathrm{f}_{\mathrm{u} \text {,cell }}$ for highly lipophilic drugs as compared to calculations based on $\log \mathrm{D}$. This indicates the importance of using a cellular matrix with relevant lipid and protein binding sites of drugs for the determination of $\mathrm{f}_{\mathrm{u} \text {,cell }}$ (8). Moreover, no significant inter-species variability in $\mathrm{f}_{\mathrm{u}, \text { cell }}$ has been observed in a recent comparative study (34). Therefore, for the four reference compounds, the methodological differences were more significant than the expected interspecies variability in $f_{u, c e l l}$, and we used our experimental $f_{u, c e l l}$ values for determination of $\mathrm{Kp}_{\mathrm{uu}}$ in both rat and human. On the other hand, inter-species variability is expected in $\mathrm{Kp}$ values, which can be influenced by active uptake and elimination processes. Therefore, the specific Kp in rat or human hepatocytes was used for determination of $\mathrm{Kp}_{\mathrm{uu}}$ (Table S3). For the four reference compounds, Kp for the human and rat hepatocytes followed the same rank order and were in the same order of magnitude, with slightly higher values in rat hepatocytes for three out of the four compounds. It should be noted that clarithromycin is a weak base that can be subject to lysosomal trapping. Using $\mathrm{pH}$ partitioning theory (18), the calculated cytosolic $\mathrm{Kp}_{\mathrm{uu}}$ (or $\mathrm{F}_{\text {cyto }}$ ) in human hepatocytes would result in 1.3 , instead of the experimental value of 2.7 , which does not account for subcellular localization of the drug.

Two of the four reference compounds, enoxacin and clarithromycin, displayed a $\mathrm{K}_{\mathrm{i}}$ ratio $\left(\mathrm{K}_{\mathrm{i}, \mathrm{mic}} / \mathrm{K}_{\mathrm{i} \text {,hep }}\right)$ or $\mathrm{IC}_{50}$ ratio and $\mathrm{Kp}_{\mathrm{uu}}$ above one, indicating a concentrative uptake of the compounds in hepatocytes. By contrast, the $\mathrm{K}_{\mathrm{i}}$ ratio or $\mathrm{IC}_{50}$ ratio and $\mathrm{Kp}_{\mathrm{uu}}$ were less than one for saquinavir and nelfinavir, suggesting that the lower potency in rat hepatocytes was driven by poor access to the intracellular compartment (and to the CYP enzyme) as opposed to the microsomes where the CYP enzyme is freely exposed in the medium. For three out of the four compounds, $\mathrm{K}_{\mathrm{i}}$ or $\mathrm{IC}_{50}$ values in liver microsomes and hepatocytes were in good agreement after applying relevant $\mathrm{Kp}_{\mathrm{uu}}$ and $f_{u, \text { mic }}$ as scaling factors (Fig. 1c) (34-36). For nelfinavir, scaling $K_{i}$ or $\mathrm{IC}_{50}$ values with $\mathrm{Kp}_{\mathrm{uu}}$ and $\mathrm{f}_{\mathrm{u} \text {,mic }}$ resulted in a larger discrepancy rather than an improvement. Interestingly, nelfinavir was identified as an outlier also in our previous $\mathrm{Kp}_{\mathrm{uu}}$ studies in MDCK cells, suggesting the involvement of unknown active processes that are not captured by the $\mathrm{Kp}_{\mathrm{uu}}$ methodology (7). Nelfinavir is very lipophilic, poorly soluble, and a substrate of active efflux (P-gp) — these properties suggest that the compound is prone to nonspecific binding and that there are significant confounding effects occurring in the hepatocyte experiment. Indeed, poor mass balance $(\sim 50 \%)$ was observed for nelfinavir and the similarly lipophilic saquinavir in the hepatocyte experiments. As the mass balance was recovered in the presence of the CYP inhibitor ABT, this confirms that the loss of compound is due to hepatic metabolism (Fig. S4). The hepatocyte metabolism of nelfinavir and saquinavir has been reported previously in a study that identified these two compounds as outliers. This was based on their intrinsic clearance in microsomes being much higher than in hepatocytes, compared to other compounds with similar clearance mechanisms (37).

It should be noted, however, that in our studies, the hepatocyte metabolism of nelfinavir and saquinavir was not a limiting factor for establishing the concentration equilibrium, since Kp values were unaffected by the presence or absence of ABT (Fig. S4). Furthermore, the use of albumin or an increase in temperature of wash buffers from 4 to $37^{\circ} \mathrm{C}$ $(38,39)$ did not change the results significantly (Fig. S5), which precludes the likelihood that non-specific binding was affecting the results. Thus, the discrepancy in the $K_{i, c o r r}$ values of nelfinavir could not be explained by CYP-mediated metabolism or non-specific binding and is likely driven by other factors. Despite the discrepancy for nelfinavir, we overall obtained a significant harmonization of the $\mathrm{K}_{\mathrm{i}}$ ratios between microsomes and hepatocytes, suggesting the validity of this approach and indicating the value of further elaboration.

In the next set of experiments, we therefore harmonized the experimental conditions between the CYP inhibition experiments and the $\mathrm{Kp}_{\mathrm{uu}}$ experiments. Instead of comparing $\mathrm{Kp} \mathrm{pu}_{\mathrm{u}}$ to $\mathrm{CYP}$ inhibition constants from the literature, we determined $\mathrm{IC}_{50}$ in $\mathrm{HH}$ and HLM with methodologies as similar as possible to each other to generate a consistent dataset. As a result, the $\mathrm{Kp}_{\mathrm{uu}}$ and $\mathrm{f}_{\mathrm{u}, \mathrm{mic}}$-corrected $\mathrm{IC}_{50}$ values for the discovery series of CYP2C9 enzyme inhibitors were in excellent agreement for HH and HLM (Fig. 2e). We conclude that the best agreement between the two systems is obtained by applying simultaneous correction factors for both systems, along with taking into consideration differences in assay setup and inter-batch variability.

Given the significance of $\mathrm{Kp}_{\mathrm{uu}}$ in the two series of in vitro experiments, we next evaluated if it could also be used as a scaling factor in in vivo studies. More specifically, we investigated if $\mathrm{Kp}_{\mathrm{uu}}$ could be used to estimate the empirical hepatic uptake scalar required in PBPK models of ketoconazole, itraconazole, and posaconazole as CYP inhibitors. Many models use such empirically determined scalars (Fig. 3a). However, others avoid them because the uptake mechanism of these azole compounds are not mediated via classic hepatic uptake transporters such as the OATP or OCT transporter family $(29,40)$. $\mathrm{Kp}_{\mathrm{uu}}$ is a measure of all combined effects in a cell and provides a mechanistic tool for estimation of uptake scalars without the need for elucidating the underlying factors contributing to the net drug disposition in the cell. We found that $\mathrm{Kp}_{\mathrm{uu}}$ values in suspended $\mathrm{HH}$ were in good agreement with the empirically determined hepatic uptake scalars in the models for both rat and human (Fig. 3). In the case of itraconazole, the three major metabolites are equally or more potent inhibitors of CYP3A4 than the parent compound, which is a complicating factor in PBPK modeling $(28,40,41)$. The measurement of $\mathrm{Kp}_{\mathrm{uu}}$ of the parent compound alone was however sufficient for recovering the hepatic uptake scalars. Therefore, we believe that $\mathrm{Kp}_{\mathrm{uu}}$ can be rationally integrated into prospective PBPK modeling approaches. The use of $\mathrm{HH}$ instead of its rat counterpart reduces the potential effects of inter-species differences in drug transporter expression and metabolic enzyme sensitivity to inhibition. It is also the most relevant in vivo model system for making extrapolations to humans. The relevance of $\mathrm{Kp}_{\mathrm{uu}}$ to in vivo studies is further supported by a recent study in which a series of four statins was assessed for in vitro and in vivo liver enrichment (35); in vivo liver-to-plasma, $\mathrm{Kp}_{\mathrm{uu}}$ in rat and 
hepatocytes
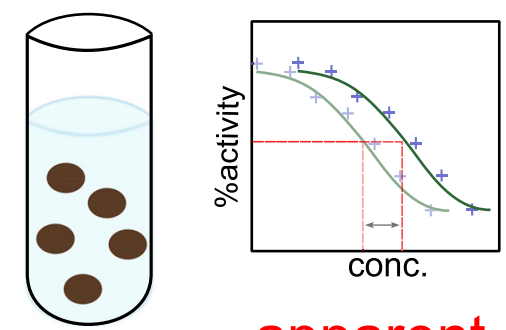

conc.

\section{apparent}
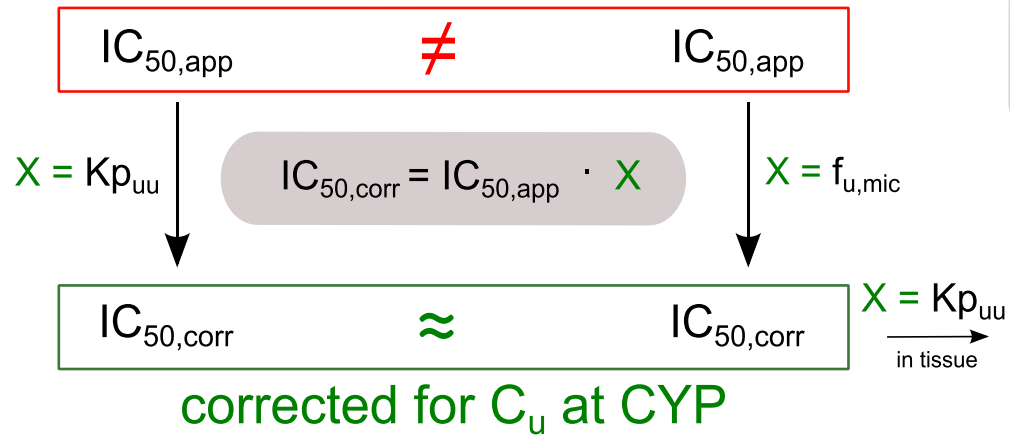

Relevance of $\mathrm{Kp}_{\mathrm{uu}}$ for CYP enzyme inhibtion

$\mathrm{Kp}_{\mathrm{uu}} \sim 1$ [0.5 to 2]: equal $\mathrm{IC}_{50}$ anticipated

- passive distribution dominates equilibrium

$\mathrm{Kp}_{\mathrm{uu}}>2$ : higher $\mathrm{IC}_{50}$ in microsomal assay

- substrate of uptake transporter?

- subcellular sequestration?

$\mathrm{Kp}_{\mathrm{uu}}<0.5$ : lower $\mathrm{IC}_{50}$ in microsomal assay

- substrate of efflux transporter?

- poor permeability?

- significant metabolism?

- high non-specific binding?

Fig. 4. Summary of use and interpretation of $\mathrm{Kp}_{\mathrm{uu}}$ in the context of CYP-mediated DDI

human were in good agreement with in vitro $\mathrm{Kp}_{\mathrm{uu}}$ obtained in cryopreserved suspended hepatocytes. Similar scenarios are anticipated for, e.g., rifampicin, which has an empirical hepatic uptake scalar of 16.9 (42) and for bosentan, with a hepatic uptake scalar of 5 to $6(43)$.

Determination of $\mathrm{K}_{\mathrm{i} \text {,app }}$ directly in $\mathrm{HH}$ can be an alternative to the incorporation of hepatic uptake scalars. However, most $\mathrm{K}_{\mathrm{i}}$ screens are based on HLM. To make our approach more generally applicable, we suggest the use of $\mathrm{K}_{\mathrm{i} \text {,corr }}$ values, and account for intracellular unbound concentrations in the target cells in any tissue of interest (Fig. 4). Our approach is not limited to the liver and can be applied on any cell of interest with an intracellular target, including studies of DDIs in intestinal enterocytes.

\section{CONCLUSION}

In summary, our results indicate that $\mathrm{Kp}_{\mathrm{uu}}$ in $\mathrm{HH}$ is an easy-to-interpret in vitro parameter that can be used as a human-relevant scaling factor to bridge the differences of experimental systems such as liver microsomes and hepatocytes and gives a mechanistic understanding of any result discrepancies (Fig. 4). Since $\mathrm{Kp}_{\mathrm{uu}}$ is the net result of all processes that affect the intracellular unbound drug concentration in $\mathrm{HH}$, no prior knowledge of uptake and elimination processes is required. Indeed, very high or low $\mathrm{Kp}_{\mathrm{uu}}$ values can indicate that active cellular processes are playing a significant role in drug disposition. Therefore, $\mathrm{Kp}_{\mathrm{uu}}$ can be used as a decision tool (e.g., if the $\mathrm{Kp}_{\mathrm{uu}}$ is lower than 0.5 or higher than 2) for more detailed investigations. Very lipophilic compounds have been found to be more challenging for assessment of $\mathrm{Kp}_{\mathrm{uu}}$ and future work should focus on this compound class. Further, $\mathrm{Kp}_{\mathrm{uu}}$ has been shown to reflect hepatic uptake scalars used in literature for the triazole antifungal family and we believe that the use of $K \mathrm{puu}_{\mathrm{uu}}$ is an approach that can be pursued to provide a mechanistic understanding of scalars used in PBPK models that predict drug exposure and DDI potential.

\section{ACKNOWLEDGMENTS}

We thank Manfred Kansy for continuous support in this project. We thank Isabelle Walter, Vincent Monin, and Urs Bader for bioanalytical support. We thank Elisa Di Lenarda, Anne-Christine Cascais, and Marie-Elise Brun for support in permeability screens of RO compounds.

\section{FUNDING INFORMATION}

This study was financially supported by ARIADME, a European FP7 ITN Community's Seventh Framework Program, grant no. 60751 (Andrea Treyer) and the Swedish research Council grants no. 2822 and 2017-01951 (Per Artursson).

Open Access This article is distributed under the terms of the Creative Commons Attribution 4.0 International License (http://creativecommons.org/licenses/by/4.0/), which permits unrestricted use, distribution, and reproduction in any medium, provided you give appropriate credit to the original author(s) and the source, provide a link to the Creative Commons license, and indicate if changes were made.

\section{REFERENCES}

1. Obach RS. Predicting drug-drug interactions from in vitro drug metabolism data: challenges and recent advances. Curr Opin Drug Discov Dev. 2009;12(1):81-9.

2. Min JS, Bae SK. Prediction of drug-drug interaction potential using physiologically based pharmacokinetic modeling. Arch Pharm Res. 2017;40(12):1356-79. 
3. Sekiguchi N, Higashida A, Kato M, Nabuchi Y, Mitsui T, Takanashi K, et al. Prediction of drug-drug interactions based on time-dependent inhibition from high throughput screening of cytochrome P450 3A4 inhibition. Drug Metab Pharmacokinet. 2009;24(6):500-10.

4. Zhuang $\mathrm{X}, \mathrm{Lu}$ C. PBPK modeling and simulation in drug research and development. Acta Pharm Sin B. 2016;6(5):43040.

5. Hewitt NJ, Lechon MJ, Houston JB, Hallifax D, Brown HS, Maurel P, et al. Primary hepatocytes: current understanding of the regulation of metabolic enzymes and transporter proteins, and pharmaceutical practice for the use of hepatocytes in metabolism, enzyme induction, transporter, clearance, and hepatotoxicity studies. Drug Metab Rev. 2007;39(1):159-234.

6. Cantrill C, Houston JB. Understanding the interplay between uptake and efflux transporters within in vitro systems in defining hepatocellular drug concentrations. J Pharm Sci. 2017;106(9):2815-25.

7. Mateus A, Treyer A, Wegler C, Karlgren M, Matsson P, Artursson P. Intracellular drug bioavailability: a new predictor of system dependent drug disposition. Sci Rep. 2017;7:43047.

8. Treyer A, Mateus A, Wisniewski JR, Boriss H, Matsson P, Artursson P. Intracellular drug bioavailability: effect of neutral lipids and phospholipids. Mol Pharm. 2018;15(6):2224-33.

9. Jones HM, Chen Y, Gibson C, Heimbach T, Parrott N, Peters SA, et al. Physiologically based pharmacokinetic modeling in drug discovery and development: a pharmaceutical industry perspective. Clin Pharmacol Ther. 2015;97(3):247-62.

10. Iwasaki S, Hirabayashi H, Funami M, Amano N. Unbound liver concentration is the true inhibitor concentration that determines cytochrome P450-mediated drug-drug interactions in rat liver. Xenobiotica. 2017;47(6):488-97.

11. Kato M, Shitara Y, Sato H, Yoshisue K, Hirano M, Ikeda T, et al. The quantitative prediction of CYP-mediated drug interaction by physiologically based pharmacokinetic modeling. Pharm Res. 2008;25(8):1891-901.

12. Lu C, Miwa GT, Prakash SR, Gan LS, Balani SK. A novel model for the prediction of drug-drug interactions in humans based on in vitro cytochrome p450 phenotypic data. Drug Metab Dispos. 2007;35(1):79-85.

13. Mao J, Mohutsky MA, Harrelson JP, Wrighton SA, Hall SD. Prediction of CYP3A-mediated drug-drug interactions using human hepatocytes suspended in human plasma. Drug Metab Dispos. 2011;39(4):591-602.

14. Riccardi K, Li Z, Brown JA, Gorgoglione MF, Niosi M, Gosset $\mathrm{J}$, et al. Determination of unbound partition coefficient and in vitro-in vivo extrapolation for SLC13A transporter-mediated uptake. Drug Metab Dispos. 2016;44(10):1633-42.

15. Riede J, Camenisch G, Huwyler J, Poller B. Current in vitro methods to determine hepatic Kpuu: a comparison of their usefulness and limitations. J Pharm Sci. 2017;106(9):2805-14.

16. Yoshikado T, Toshimoto K, Nakada T, Ikejiri K, Kusuhara H, Maeda K, et al. Comparison of methods for estimating unbound intracellular-to-medium concentration ratios in rat and human hepatocytes using statins. Drug Metab Dispos. 2017;45(7):77989.

17. Guo Y, Chu X, Parrott NJ, Brouwer KLR, Hsu V, Nagar S, et al. Advancing predictions of tissue and intracellular drug concentrations using in vitro, imaging and PBPK modeling approaches. Clin Pharmacol Ther. 2018.

18. Mateus A, Matsson P, Artursson P. Rapid measurement of intracellular unbound drug concentrations. Mol Pharm. 2013;10(6):2467-78.

19. Mateus A, Gordon LJ, Wayne GJ, Almqvist H, Axelsson H, Seashore-Ludlow B, et al. Prediction of intracellular exposure bridges the gap between target- and cell-based drug discovery. Proc Natl Acad Sci U S A. 2017;114(30):E6231-9.

20. Brown HS, Wilby AJ, Alder J, Houston JB. Comparative use of isolated hepatocytes and hepatic microsomes for cytochrome P450 inhibition studies: transporter-enzyme interplay. Drug Metab Dispos. 2010;38(12):2139-46.

21. Parker AJ, Houston JB. Rate-limiting steps in hepatic drug clearance: comparison of hepatocellular uptake and metabolism with microsomal metabolism of saquinavir, nelfinavir, and ritonavir. Drug Metab Dispos. 2008;36(7):1375-84.
22. Cleary Y, Gertz M, Morcos PN, Yu L, Youdim K, Phipps A, et al. Model-based assessments of CYP-mediated drug-drug interaction risk of alectinib: physiologically based pharmacokinetic modeling supported clinical development. Clin Pharmacol Ther. 2017.

23. Gillen CM, Forbush B 3rd. Functional interaction of the K-Cl cotransporter (KCC1) with the Na-K-Cl cotransporter in HEK293 cells. Am J Phys. 1999;276(2 Pt 1):C328-36.

24. Mateus A, Matsson P, Artursson P. A high-throughput cellbased method to predict the unbound drug fraction in the brain. J Med Chem. 2014;57(7):3005-10.

25. Law V, Knox C, Djoumbou Y, Jewison T, Guo AC, Liu Y, et al. DrugBank 4.0: shedding new light on drug metabolism. Nucleic Acids Res. 2014;42(Database issue):D1091-7.

26. Benet LZ, Broccatelli F, Oprea TI. BDDCS applied to over 900 drugs. AAPS J. 2011;13(4):519-47.

27. Vermeer LM, Isringhausen CD, Ogilvie BW, Buckley DB. Evaluation of ketoconazole and its alternative clinical CYP3A4/5 inhibitors as inhibitors of drug transporters: the in vitro effects of ketoconazole, ritonavir, clarithromycin, and itraconazole on 13 clinically-relevant drug transporters. Drug Metab Dispos. 2016;44(3):453-9.

28. Isoherranen N, Kunze KL, Allen KE, Nelson WL, Thummel KE. Role of itraconazole metabolites in CYP3A4 inhibition. Drug Metab Dispos. 2004;32(10):1121-31.

29. Higgins JW, Ke AB, Zamek-Gliszczynski MJ. Clinical CYP3A inhibitor alternatives to ketoconazole, clarithromycin and itraconazole, are not transported into the liver by hepatic organic anion transporting polypeptides and organic cation transporter 1. Drug Metab Dispos. 2014;42(11):1780-4.

30. Yamano K, Yamamoto K, Kotaki H, Sawada Y, Iga T. Quantitative prediction of metabolic inhibition of midazolam by itraconazole and ketoconazole in rats: implication of concentrative uptake of inhibitors into liver. Drug Metab Dispos. 1999;27(3):395-402.

31. Farowski F, Cornely OA, Vehreschild JJ, Hartmann P, Bauer T, Steinbach A, et al. Intracellular concentrations of posaconazole in different compartments of peripheral blood. Antimicrob Agents Chemother. 2010;54(7):2928-31.

32. Filppula AM, Parvizi R, Mateus A, Baranczewski P, Artursson P. Improved predictions of time-dependent drug-drug interactions by determination of cytosolic drug concentrations. Sci Rep. 2019;9(1):5850.

33. Kilford PJ, Gertz M, Houston JB, Galetin A. Hepatocellular binding of drugs: correction for unbound fraction in hepatocyte incubations using microsomal binding or drug lipophilicity data. Drug Metab Dispos. 2008;36(7):1194-7.

34. Riccardi K, Ryu S, Lin J, Yates $\mathrm{P}$, Tess $\mathrm{D}$, Li R, et al. Comparison of species and cell-type differences in fraction unbound of liver tissues, hepatocytes, and cell lines. Drug Metab Dispos. 2018;46(4):415-21.

35. Riccardi K, Lin J, Li Z, Niosi M, Ryu S, Hua W, et al. Novel method to predict in vivo liver-to-plasma Kpuu for OATP substrates using suspension hepatocytes. Drug Metab Dispos. 2017;45(5):576-80.

36. Rodgers T, Jones HM, Rowland M. Tissue lipids and drug distribution: dog versus rat. J Pharm Sci. 2012;101(12):4615-26.

37. Di L, Keefer C, Scott DO, Strelevitz TJ, Chang G, Bi YA, et al. Mechanistic insights from comparing intrinsic clearance values between human liver microsomes and hepatocytes to guide drug design. Eur J Med Chem. 2012;57:441-8.

38. Francis GL. Albumin and mammalian cell culture: implications for biotechnology applications. Cytotechnology. 2010;62(1):116.

39. Sun Y, Chothe PP, Sager JE, Tsao H, Moore A, Laitinen L, et al. Quantitative prediction of CYP3A4 induction: impact of measured, free, and intracellular perpetrator concentrations from human hepatocyte induction studies on drug-drug interaction predictions. Drug Metab Dispos. 2017;45(6):692-705.

40. Prieto Garcia L, Janzen D, Kanebratt KP, Ericsson H, Lennernas H, Lundahl A. Physiologically based pharmacokinetic model of itraconazole and two of its metabolites to improve the predictions and the mechanistic understanding of CYP3A4 drug-drug interactions. Drug Metab Dispos. 2018;46(10):1420-33. 
41. Templeton IE, Thummel KE, Kharasch ED, Kunze KL, Hoffer C, Nelson WL, et al. Contribution of itraconazole metabolites to inhibition of CYP3A4 in vivo. Clin Pharmacol Ther. 2008;83(1):77-85.

42. Varma MV, Lai Y, Kimoto E, Goosen TC, El-Kattan AF, Kumar V. Mechanistic modeling to predict the transporter- and enzyme-mediated drug-drug interactions of repaglinide. Pharm Res. 2013;30(4):1188-99.
43. Sato M, Toshimoto K, Tomaru A, Yoshikado T, Tanaka Y, Hisaka A, et al. Physiologically based pharmacokinetic modeling of bosentan identifies the saturable hepatic uptake as a major contributor to its nonlinear pharmacokinetics. Drug Metab Dispos. 2018;46(5):740-8.

Publisher's Note Springer Nature remains neutral with regard to jurisdictional claims in published maps and institutional affiliations. 